week) conftrolled trials of schizophrenic inpatients (SEe CLINICAL PHARMACOLOGY). The effectiveness of SEROOUEL in long-term use, that is, tor more than 6 weeks. has not been systematically evaluated in controlled trals. Theretiore, the phyyician
who elects to use SEROOUEL for extended periods should period cally re-evaluate who elects to use SEROOUEL for extended periods should period
the long-term usetulness of the drug for the individual patient
CONTRAINDICATIONS

indicated in indivicuals with a known hypersensitivity to this

WARNINGS

Neuroleptic Malignant Syndrome: (MMS) A potentially tatal symptom complex

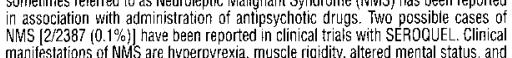
evidence of autoromici instability (irregular pulse or blood pressure, tachycardia,

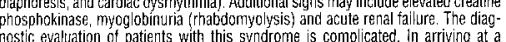
diasnosis, it is important to exclude cases whtere the clinical presentation includes
hoth serious medical illness (e.g., pneumonila, systemic intection, etc.) and untraaled or inadequately treated extrapyramidal signs and symptoms i EPS. Other important
considerations in the differential diagnosis include central anticholinergic toxicity. heat stroke, drug fever and primary central nerveos system (CNS) patholoogy. The
managerment of MMS should include: 1 immediate discontinuation of antipsychotic drugs and other drugs not essential to concurrent therapy 2) intensive symptomatic
treatment and medical monitoring; and 3) treatrment of aryy concorm tant serious medical probiems tor which specific treatments are available. There is no general requires antipsychotic drug treatment after recovery from NMS, the potential fein-
troduction of drug therapy should be carefully considered. The patient should be

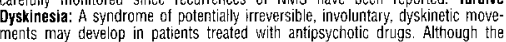
prevalence of the syndrome appears to be highest among the elderly, especially

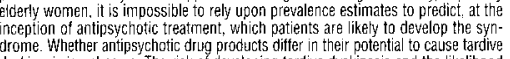
dyskinesia is unknown The risk or developing tardive dyskinesia and the likelihood
that it will become irreversibbe are telievedt to increase as the duration of treatment

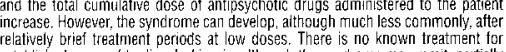

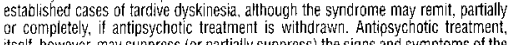
itself, however, may suppress lor partially suppress) the signs and symptoms of the
syndrome and thereby may possibly mask the underlying process. The effect that symptomatic suppression has upon the long-term course of the syndrome is
unknown. Given these considerations, SERooleL should be prescribed in a manner that is most likely to minimize the occurrence of tardive dyskinesia. Chronic antipsya chromic Illness that (1) is known to respond to antipsychotic crugs, and (2) for
whom allemal ive, equally effective, but potentially less harmful treatrments are not avalable or appropriate. In patients who $\mathrm{co}$ require chronic treatrment, the smallest
dose and the shortest duration of treatment producing a satisfactory clinical response should be sought. The need for continued treatment should be reassessed SEROQUEL, drug ciscontinuation should be considered. However, some patients
may require treatment with SEROQUEL despite the presence of the syndrome.
PRECAUTIONS: General Orthostatic Hypotension: SEROCUEL may induce orthostatic hypotension assothe initial dose-titration period, probably retlecting its $\alpha$, -adrentergic antagonist
properties. Syncope was reported in $1 \%$, (22:2162) of the patients treated with active control drugs. The risk of orthosiatic hypotension and syncope may be

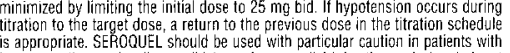
is appropriate. SEROQUEL Should be used with partc ula catulion in parients with
known cardiovascular disease (history of myocardial infarction or ischemic heart citions which would predispose patients to thypotension (dehydration, hypoyolemia

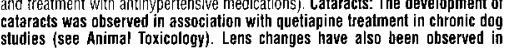
studies (see Animal Toxicology). Lens thanges have also been observed in
patients during long.term SEROQuEL treatment, but a causal relationship to lenticular changes cannot be excluded at this time. Therefore, examinatior of
the lens by methods adequate to detect cataract formation, such as slit lamp
exam or other appropriately sensitive methods, is recommended at initiation of exam or other appropriately sensitive methods, is recommended at initiation of
ireatment or shorly thereatter, and at 6 month intervals dering chronic treatiment.

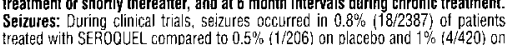

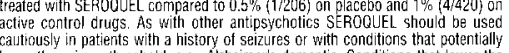
lower the seizure threshold, e.g. Alzheimer's dementia. Conditions that lower the
seizure threshold may be more prevalent in a population of 65 years or odder.

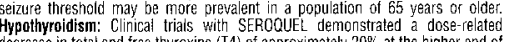
decrease in total and free thyyoxine (T4) of approximately $20 \%$ at the higher end of ment and maintained without adaptation or progression during more chronic therapy. in most patients. and levels of TBG were unchanged. In nearly all cases, cessation
of SEROOUEL treatment was associated with a reversal of the efitects on total and tree T4, irrespective of the duration of treatment. About $0.4 \%$ (10/2386) of
SEROCLLL patients did experience TSH increases. Six of the patients with ISH
increases needed replacement thyroid treatment. Choolesterol and Triglyceride

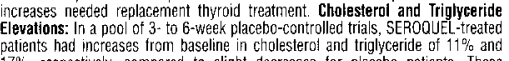
$17 \%$, respectively, cormpared to slight decreases tor placebo patients. Thess
changes were only weakly related to the increases in weight observed in SEROGIELL-

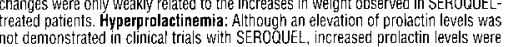
observed in rat studies with this compound, and were associated with an increase ments indicate that approximately one-third of human breast cancers are prolactin
dependent if vitro, a factor of potential importance if the prescription of these druggs is contemplated in a patient with previously detected breast cancer. Although
disturbances such as galactorthea, amenormear gynecomastia, and impotence have been reported with prolactin-elevating compounds, the clinical signifiticance of
eievated serum prolactin levels is unkrown for most patients. Neither clirical studies

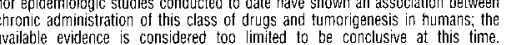
available evidence is considered too limited to be conclusive at this time.
Transaminase Elevations: Asymptomatic, transient and reversible elevations in

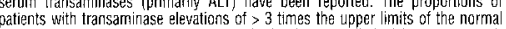
reference range in a pool of 3 . to 6 -week p placebo-controlted trials were approxielevations usually occurred within the tirst 3 weeks of drug treatment and promptly Cognitive and Motor Impairment: Somnolence was a commonly reported adverse
event reported in patients treated with SERCOUEL especially during the $3-5$ day event reported in patients treated with SERCOUEL especiallyy during the $3-5$ day
period of initial dose-titration. In the $3-106$ - week placeto-controlled trials, ssmnolence was reported in $18 \%$ of patients on SEROQUEL Compared to $11 \%$ of placebo
patients. Since SEROQUEL has the potentia to impair judgment, thinking, or molor alertress, such as operating a motor yehicle (including automobiles) or operating hazardous machinery until| they are reasonably certain that SEROQUEL therapy SEROOUEL has been reported prior to market introduction. While a calsal relation-
ship to use of SEROOUEL has not been established other rougs with possible that SEROQLELL may share this capacity. Severe priapism may require possible that SEROduct may share this capacity. Severe priapism may require SEROCUEL, discuption of the body's ability to reduce core body temperature has
been altributed to antipsychotic agents. Appropriate care is advised when prescribing to an elevation in core body temperature, e.g. axercising strenuously, exposure to

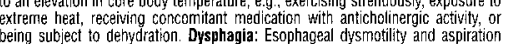

SEROQUEL ${ }^{\text {"ni }}$ (quetiapine fumarate) Tablets

have been asscciated with antipsychotic drug use. Aspiration pneumonia is a common
cause of morbidity and morrality in elderly patients, in particular those with

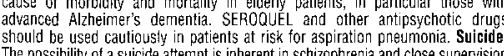
The possibility of a suicide attermpt is intherent in schizophrenia and clase supervision of high nisk patients should accompany drug therapy. Prescriptions tor SEROQuEL
should be written for the smallest quantity of tablets consistent with good patient
managemement in order to reduce the risk of overed oss. Use in Patients with management in order to reduce the risk of Overdose. Use in Patients with
Concomitant IIIness: Clinical experience with SEROOUEL in patients with certain
concomitant systemic illnesses is limited. SEROODUEL has not been evaluated or used to any appreciable exlent in patients with a recent history of myocardial infarc-
tion or unstable heart disense. Patients with these diagnoses were exciuded from premarketing clinical studies. Because of the risk of orthostatic hypotension with
SEFOCUEL, caution should be observed in carciac patients (see Orthostatic Hypotension). Intormation for Patients: Physicians are advised to discuss the
following issues with patients for whom they prescribe SEROOUUEL. Orthostatic Hypotension: Patients should be advised of the risk of orthostatic hypotension
especially during the $3-5$ day period of initial dose titration, and also at times e-initiating treatment or increases in dose. Interference with Cognitive and Moto Performanne: Since somnolence was a commently reporled adverse event associater
with SEROOUEL treatment, patients should be advised of the risk of samnolence,

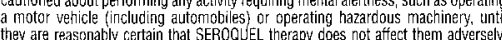

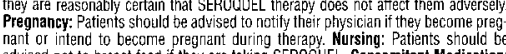
nant or intend to become pregnant during therapyy Mursing: Patients should be
advised not to breast feed if they are taking SEROQUEL. Conconitant Medication
As with other medications, patients shoulda be advised to notity their physicians

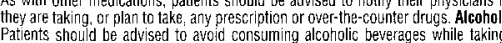
Patients should be advised to avoid consuming alcoholic beverages while taking
SEROCUEE. Heat Exposure and Dehydration: Patients should be advised regarding
appropriate care in avoiding overheating and dehycration. Laboratory Tests: No approppiate Gare in avoiding overheating and dehydration. Laboratory Tests: N
specific laboratory tests are recommended. Drug Interactions: The risks of using

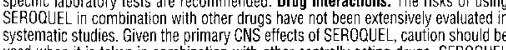
used when it is taken in combination with other centrally acting drugs. SEROQUEL. with selected psychotic disorders, and alcoholic beverages should be avoided whit
taking SEROQUEL. Because of its potent al for inducing hypotension, SEROQUE laking
may enhance the effects of certain antihypertensive agents. SEROQUUEL may antag-
onize the effects of tevodopa and dopamine agonists. The EEfect of Other Drugs on

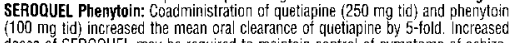

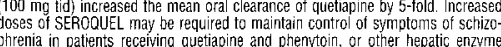

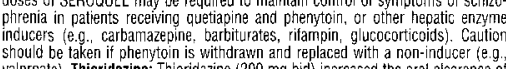

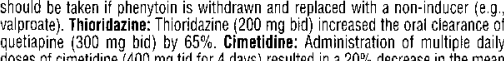

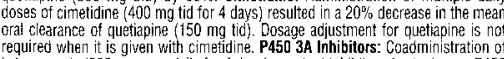

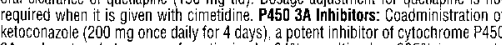

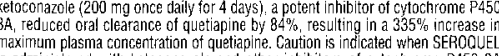

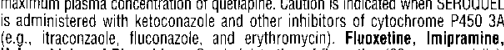

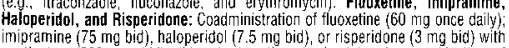

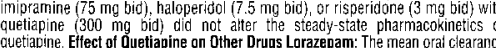

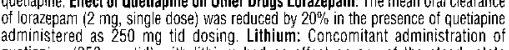

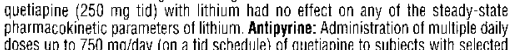
psychotic disorders had no clinically redevant effect on the to clearance of antipyrine or

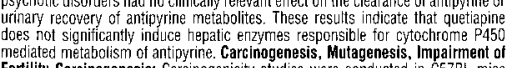

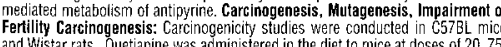
and Wistar rats. Quetiapine was adminisistered in the diet to mice at doses of 20.75 ,
250 , and $750 \mathrm{mg}, \mathrm{kg}$ and to rats by gavage at doses of 25,75 , and $250 \mathrm{mg} / \mathrm{kg}$ for
two years. These doses are equivalent to $0.1,0.5,1.5$, and 4.5 times the maximum

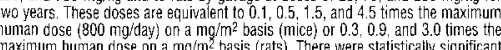
maximum human dose on a $\mathrm{mg} / \mathrm{m}^{2}$ basis (rats). There were statistically signitican
increases in thyroid gland tolitiuar adencmas in male mice at doses of 250 and 750 mogkg or 1.5 and 4.5 times the maximum human dose on a mg/ma 2 basis and
in male rats at a dose of $250 \mathrm{mg} / \mathrm{kg}$ or 3.0 times the maximum human dose on a

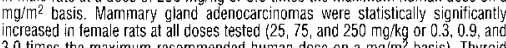
follicular cell adenomas may have resulted from chronic stimulation of the thyroid gland by thyroid stimulating hornone (ISH) resulting from enthanced metabolism
and clearance of thyroxine by rodent liver Changes in TSH, thyroxine, and thyroxing
clearance consistent with this mechanism were observed in subchronic toxicity

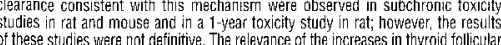
cell adenomas to human risk, through whatever mechanism. is unknown.
Antipsychotic drugs have been shown to chronically elevate prolactin levels in rodents. Serum measurements in a 1-yr toxicity study showed that quetiapine
increased median serum prolactin levels a maximum of 32 -and 13 -fold in male and temale rats, respectively. Increases in mammary neoplasms have been found in
rodents atter chronic administration of otmer antipsychotic drugs and are considered

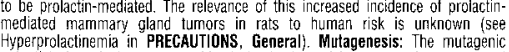

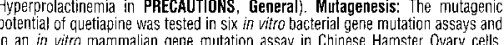

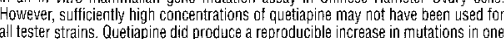

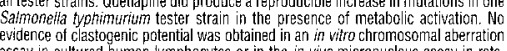
assay in cultured human tymphocytes or in the in vivo micronucleus assay in rats.

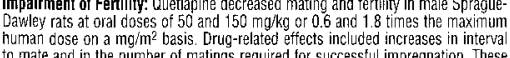
to mate and in the number of matings required tor successtul impregnation. These
effects continued to be observed at 150 mogkg even after a two-week period without treatment. The no-eftect dose tor impaired mating and tert lity in male rats was
$25 \mathrm{mg} / \mathrm{kg}$. or 0.3 times the maximum human dose on a mag/me basis. Quetiagine

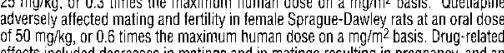
effects included decreases in matings and in matings resulting in pregnancy, and an
increase in the interval to mate. An increase in irregular estrus cycles was observed increase in the interval to mate. An increase in irregular estrus cycles was observed
at doses of 10 and $50 \mathrm{mg}, \mathrm{kg}$, or 0.1 and 0.6 times the maximum human dose on a mig/m2 basis. The no-efect dose in female rats was $1 \mathrm{mg} / \mathrm{kg}$. or 0.01 times the
maximum human dose on a mg/m2 basis. Pregnancy: Pregnancy Category C: Thie teratogeric potential of quetiapine was studied in Wistar rats and Dutch Belted rabbits

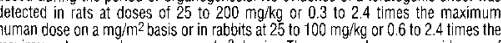
maximum human cose on a mg/m² basis. There was, howvever, evidence of
embryoffetal toxicity. Delays in skeletal cssitication were detected in rat tetuses at
doses of 50 and $200 \mathrm{mg} / \mathrm{kg} 10.6$ and 2.4 imes the maximum human dose on a

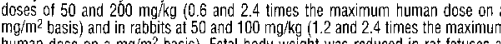
$200 \mathrm{mg} / \mathrm{kg}$ and rabbit fetuses at $100 \mathrm{mg} / \mathrm{kg}$ (2.4 times the maximum hurran dose

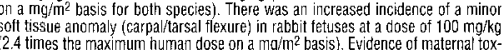

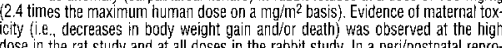
ductive study in rats, no drug-related eftects were observed at doses of 1,10 , and
20 mgakg or $0.01,0.12$ ard 0.24 times the maximum human dose on a mo:m² basis. However, in a pretimininary peritpostnatal study, there were increases in ietal
and pup death, and cecreases in mean litter weight at $150 \mathrm{mg} / \mathrm{kg}$, or $3.0 \mathrm{t}$ tmes the maximumi human dose on a mg/m² basis. There are no adequate and well-con-
trolled studies in pregnant women and quetiapine should bo used during pregnancy trolled studies in pregnant wornen and quetiapine should be used during pregnancy
only if the potential benefit justifies the potential risk to the fetus. Labor and
Delivery: The effect of SEROQUJEL on labor and delivery in humans is unkrown.
SEROQUEL ${ }^{\text {ond }}$ (quetiapine fumarate) Tablets

Nursing Mothers: SEROQUEL waS excreted in milk of treated animals duriing laclation. It is not known if SEROCQUEL is excreted in human milk. II is recommended that
women receiving SEROOUEL should not breast feed. Pediatric Use: The sadety and Use: Of the approximately 2400 patients in clinical studies with SEROQUEL, $8 \%(190)$ were 65 years of age or over. In general, there was no indication of any different
tolerability of SEROQuEL in the elderly compared to younger adults. Nevertheless, the presence of factors that might decrease pharmacokinetic clearance, increase the phar-
macodynanacic response to SEROQUEL, or cause poorer Iolerance or orthostasis. monitoring during the initial dosing period in the elderly. The mean plasma clearance
of SEROQUEL was reduced by $30 \%$ to $50 \%$ in elderly patients when compared to

\section{ADVERSE REACTIONS}

Adverse Events Occurring al an Incidence of $1 \%$ or More Among SEROQuEL
Treated Patients in Shant-Term. Placebo-Cantrolled Trials. The most common observec adverse events associted with the USe of $S E R O C U E L$ (incidence of $5 \%$ or
greater) and observed at a rate on SEROQUEL at least twice that of placebo were

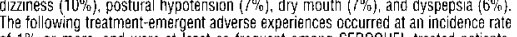
of $1 \%$ or more, and were at least as riequent among SEROOUEL treated patients,
treated at doses of 75 mog/day or greater than among placebo treated patients in

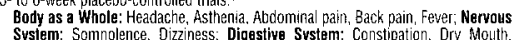

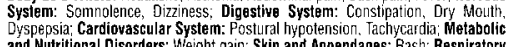
System: Rhinitis; Special Senses: Ear pain
'Events for which the SEROOLJEL incidence was equal to or less than placeho are not listed in the table, but included the following. pain, infection, chest pain, hostility.
accidental injury, hypertension, hypotension, nausea, vomiting, diarrhea. myalgia, agitation, insomnia, anxiety, nervousness, akathisia, hypertonia, tremor, depression, Explorations for interactions on the basis of gender, age, and race did not reveal any

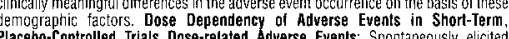
Placebr-Controlled Trials Dose-related Adverse Events: Spontaneously elicited
adverse event data from a study comparing five fixed doses of SEROQUEL (75 mg, adverse event data from a study comparing five fixed doses of SEROQUEL (75 $\mathrm{mg}$,
$150 \mathrm{mg} .300 \mathrm{mg} .600 \mathrm{mg}$. and 750 mig/day) to placebo were explored for doserelatedness of adverse events. Logistic regression anakses revealed a positive dose
response (p<0.05) for the following adverse everits: dyspepsia, abdonininal pain, and
weight gain. Extrapyramidal Symotons: Data from one f-week clinical trial comparing weight gain Extrapyramidal Symptoms: Oata from one 6 -week clinical trial comparing
five fixed doses of SEROQUEL $(75,150,300,600,750 \mathrm{mg}$, day) provided evidence for the lack of treatment-mergent extrapyramidal symptoms (EPS) and dose-relatedress EPS: (1) Simpscin-Angus total score imean thange from baseline) which evaluates

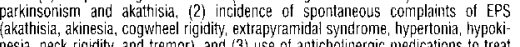

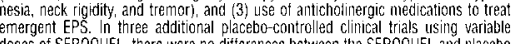

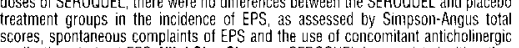
Scores, spontaneous complaints of EPS and the Use of Concomitant anticholinergic
medications to treat EPS. Vival Sign Changes: SERPQUEL is associated with ortho-
static hypotension (see PRECAUTIONS). Weight Gain: The proportions of patients

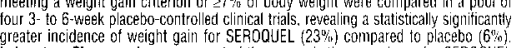

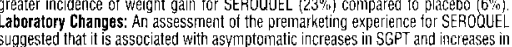

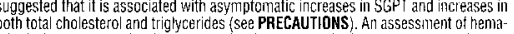

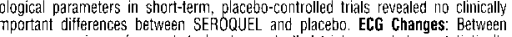
group comparisons for pooied placebo-controlled trials revealed no statistically
significant SEROQUELiplacebo differences in the proportions of patients experiencing

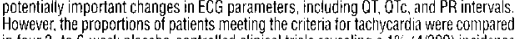
In four 3- to b-week placebo-controlled clinical frials revealing a 1\% (4/399) incidence
or SEROOUEL compared to $0.6 \%$ (11/156) incidence for placebo. SEROQUEL use was

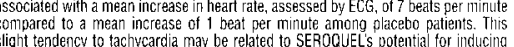

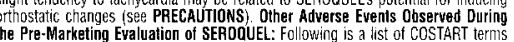
that reflect treatment-emergent adve se events as cefined in the introduction to the
ADVERSE REACTIONS section reported by patients treated with SEROOUEL at muttiple doses $\geq 75$ mg/day during any phase of a trial within the premarketing database of
approximately 2200 patients. All reported events are included except thase already listed in Table 1 or elsewnere in labeling, those events tor which: a trug cause was
remote, and those event terms which were so general as to be unintormative. It is important to emph asize that, although the events reported occurred during treatment

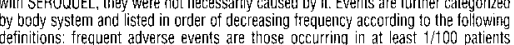
conty those not already listed in the tabulated results trom placesto-contronled trials 11000 patients; rare' events are those accurring in fewer than $1 / 1000$ patients. Nervous System: Fiequent: hypertonia, dysarthria, Infrequent abnornal dreams,
dyskinesia, thinking aonormal, tardive diyskinesia, vertigo, involtuntary movements.

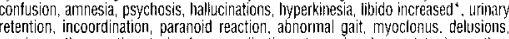
manic seaction, apathy, ataxia, depersonal ization. stupor, bruxism catatonic reaction,
hemip legia: Rare: aphasia buccoglossal syndrome, shoreathetosis. deliriumn, emo-

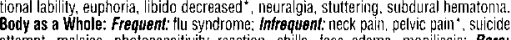
attempt, malaise, photosen sitivity reaction, chills. tace edema montiliasis: Aare:

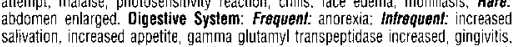

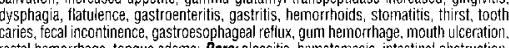

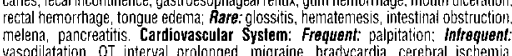

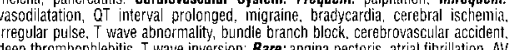

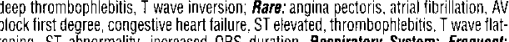
tening. ST abnormality, increased ORS duration. Aespiratory System: Froquent:
pharyngitis, rhinitits. Cough increased, dyspnea; Infrequent: pneumounia, epistaxis.
asthma; Hare: hiccup, hyperventiliation. Melabolic and Nutritional System: Frequent peripheral exdema. Intrequent: weight loss, alkaline ploss hhatase increased

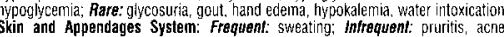

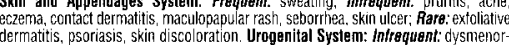

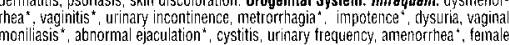

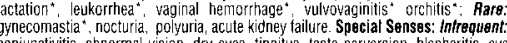
coniunctivitis, abnormal vision, dry eyes, tinnitus, taste perversion, blepharitis, eye
pain; Rare: abnormality of accommostation, deatness, glaucona. Musculoskeletalal

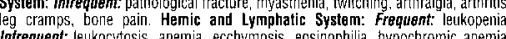

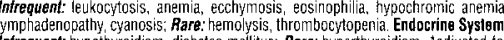
Infrequent: hypothyroidism, diabetes mellitus: Aare: hyperthyroidism, "adjusted tor
gender Post Marketing Experience: Adverse events ieported since market introduction gender Post Markeling Experience: Adverse events reported since markst introduction eukopeniafneutropenia. If a patient develops a low white cell count consider dis-

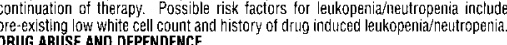
DRUG ABUSE ANO DEPENDENCE
Controlled Substance Class: SEROOUEL is not a controlled substance. 


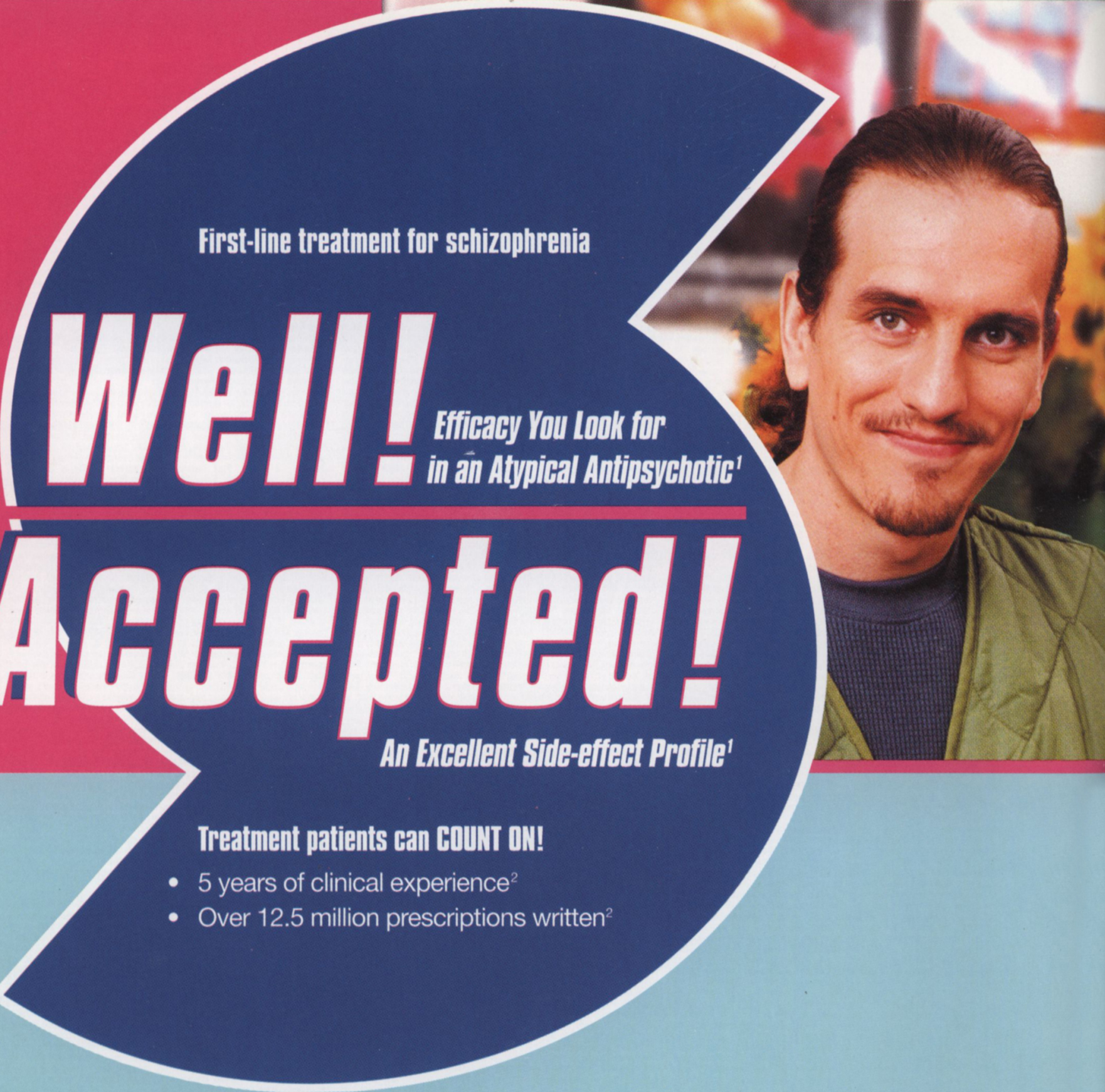

The most common adverse events associated with the use of SEROQUEL are diziness (10\%), postural hypotension (7\%), dry mouth $(7 \%)$, and dyspepsia $(6 \%)$. The majority of adverse events are mild or moderate.

In 3- to 6-week, placebo-controlled trials, the incidence of somnolence was $18 \%$ with SEROQUEL vs $11 \%$ with placebo.

As with all antipsychotic medications, prescribing should be consistent with the need to minimize the risk of tardive dyskinesia, seizures, and orthostatic hypotension.

References: 1. Prescribing Information for SEROQUEL* (quetiapine fumarate), Rev 1/01. AstraZeneca Pharmaceuticals LP. Wilmington, Delaware. 2. Data on file, IMS data, AstraZeneca Pharmaceuticals LP, Wilmington, Delaware.
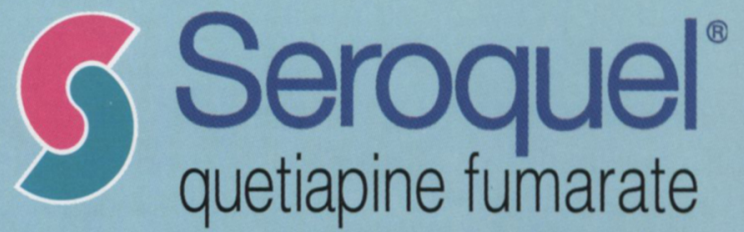

$25 \mathrm{mg}, 100 \mathrm{mg}, 200 \mathrm{mg} \& 300 \mathrm{mg}$ tablets

\section{AstraZeneca}

AstraZeneca Pharmaceuticals LP $2096919 / 02$

\section{Ireatment patients tan LIVE with!}

C 2002 AstraZeneca Pharmaceuticals LP. All rights reserved. SEROQUEL is a registered trademark of the AstraZeneca group of companies. Please see Brief Summary of Prescribing Information on following page. 